\title{
FONTES HISTÓRICAS E ÉTICO-LEGAIS: POSSIBILIDADES E INOVAÇÕES
}

Fernando Porto', Genival Fernandes de Freitas², José Siles González ${ }^{3}$ 'Prof. da Escola de Enfermagem Alfredo Pinto (EEAP) da Universidade Federal do Estado do Rio de Janeiro

${ }^{2}$ Professor Doutor do Departamento de Orientação Profissional da Escola de Enfermagem da Universidade de São Paulo.

${ }^{3}$ Professor catedrático do Departamento de Enfermería de la Universidad de Alicante (Espanha).

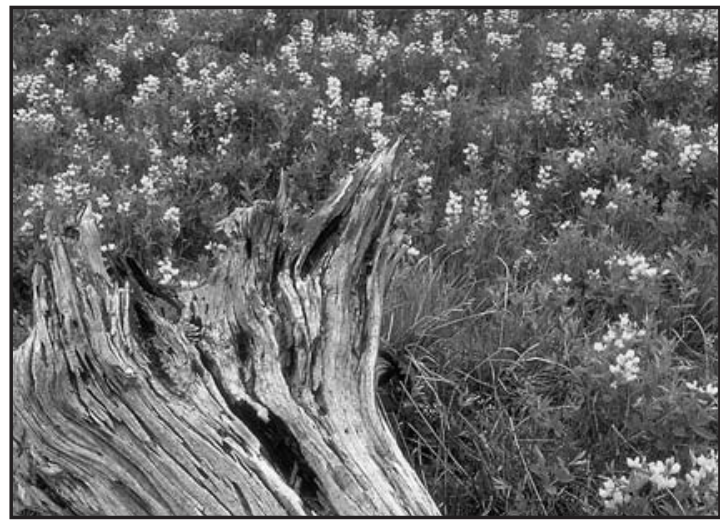

SOURCES HISTORICAL AND ETHICAL LEGAL: OPPORTUNITIES AND INNOVATIONS

\section{SUMMARY}

Introduction: This paper focused the analysis and questioning the use of historical sources and types of ethical and legal.

Objectives: Reflecting on the classification of historical and ethical-legal in the light of national and international literature and discuss opportunities and innovations in this regard.

Methodology: A descriptive, exploratory and qualitative approach.

Results and discussion: From the historical trajectory of the classification of sources, the findings indicated the need for expanding the concept of documents / sources and the possibility of articulating different sources in studies that have as object the history of nursing.

Keywords: History of nursing; Ethics; Law.

\section{FUENTES HISTÓRICAS Y ÉTICO-LEGA- LES: POSIBILIDADES E INNOVACIONES}

\section{RESUMEN}

Introducción: El estudio se centró el análisis y el cuestionamiento de la utilización de las fuentes históricas, éticas y legales.

Objetivos: Reflexionar sobre la clasificación de las fuentes históricas y ético-legales a la luz de la literatura nacional e internacional y debatir las oportunidades y las innovaciones en este sentido.

Metodología: Estudio descriptivo, exploratorio y de abordaje cualitativo.

Resultados y discusión: Desde la trayectoria histórica de la clasificación de las fuentes, los resultados revelan la necesidad de ampliar el concepto de documentos y fuentes y la posibilidad de articular las diferentes fuentes en los estudios que tienen como objeto la historia de la enfermería.

Palabras clave: Historia de la Enfermería; Ética; Legislación.

\section{RESUMO}

Introdução: $\mathrm{O}$ estudo tem como objeto a análise e problematização do uso da tipologia das fontes históricas e ético-legais.

Objetivos: Refletir sobre a classificação das fontes históricas e ético-legais à luz da literatura nacional e internacional e discorrer sobre possibilidades e inovações a esse respeito.

Metodologia: Estudo descritivo, exploratório e de abordagem qualitativa. 
Resultados e discussão: A partir da trajetória histórica da classificação das fontes, os achados apontaram para a necessidade de ampliação do conceito de documentos / fontes e a possibilidade de articulação de fontes diversas em estudos que tenham como objeto a história da enfermagem.

Palavras-chave: História da Enfermagem; Ética; Legislação.

\section{Introdução ao estudo e justificativa}

As fontes históricas e ético-legais seriam, em princípio, todo aquele objeto material, instrumento ou ferramenta, símbolo ou discurso intelectual, que procede da criatividade humana, através dos quais se pode inferir algo acerca de uma determinada situação social no tempo (Aróstegui, 2001).

A história tornou-se científica ao fazer a crítica dos documentos a que se chama "fontes". Em que consiste o fazer a crítica? O "corpus" documental (massa documental) não é qualquer coisa que fica por contado do passado; é um produto da sociedade que o fabricou segundo as relações de forças que ali detinham o poder. O termo "documentum" deriva de "docere", "ensinar", evoluiu para o significado de "prova" e é amplamente usado no vocabulário legislativo (é no século XVII que se difunde na linguagem jurídica). Assim, o documento que, para a escola histórica positivista do fim do século XIX e do início do século XX, será o fundamento do fato histórico, ainda que resulte da escolha de uma decisão do pesquisador, parece apresentar-se por si mesmo como prova histórica. Sua objetividade parece opor-se à intencionalidade do monumento..." (Le Goff, 2003). Ademais, o vocábulo "monumentum" representa um sinal do passado. Os documentos são fontes e os monumentos (uma obra comemorativa de arquitetura ou escultura; um monumento funerário) também são fontes para a história.

O monumento é tudo aquilo que pode evocar o passado perpetuar a recordação, por exemplo, os atos escritos. O monumento tem como característica o ligar-se ao poder de perpetuação, voluntária ou involuntária das sociedades históricas; é um legado à memória coletiva e possibilita o reenviar a testemunhos que só numa parcela mínima são testemunhos escritos (Le Goff, 2003).
A partir de 1960, com o advento da chamada revolução documental, houve um alargamento da compreensão do significado do termo documento: este adquiriu conotação mais ampla, ou seja, passou a ser entendido e aceito em diversas tipologias: escrita, ilustrada, transmitida pelo som, a imagem, ou de qualquer outra maneira (Samaran, 1961).

Diversas são as maneiras de classificação das fontes documentais. José González Siles (1999) relata que, a classificação é um capricho da história, pois ela deve ter utilidade prática e ser clara.

A classificação das fontes é um tipo de dado que orienta o pesquisador no momento em que decide que tipo de fonte será utilizado no estudo, bem como para responder ou contestar a perguntas formuladas com aderência ao objeto de pesquisa, com a proposta de cumprir os objetivos traçados.

Neste sentido, certa reflexão sobre a classificação das fontes se faz necessária. Quanto à hierarquização destas, alguns as classificam como primárias - contato direto com os fatos - e secundárias -contato indireto com os fatos - que, segundo José González Siles, trata-se de uma maneira obsoleta, mas isso pode ser explicado pela trajetória de classificação das fontes pelo decorrer dos séculos (Siles, 1999).

Considerando a ampliação do conceito de fonte, a generalização das possibilidades de exploração de objetos materiais ou de realidades intelectuais, como fontes de informação histórica, uma das questões prévias para o estudo profundo das fontes históricas é a de estabelecer uma taxonomia adequada da diversidade de fontes possíveis.

Nessa perspectiva, há que se mencionar, então, em critérios taxonômicos, a saber: posicional (fontes diretas ou indiretas); intencional (fontes voluntárias ou não voluntárias); qualitativo (fontes materiais ou culturais) e formal quantitativo (fontes seriadas ou não seriadas e não seriáveis) (Aróstegui, 2001).

No tocante à posição, as fontes eram de um tipo ou de outro (diretas ou indiretas), segundo a maneira como a informação era obtida, ou seja, pela "proximidade" da fonte aos fatos narrados. Nessa ótica, uma fonte seria considerada direta quando era um escrito ou relato de alguma testemunha presencial de um fato, de um protagonista, de uma documentação, que emanava diretamente do fenômeno em tela. Por sua vez, uma fonte indi- 


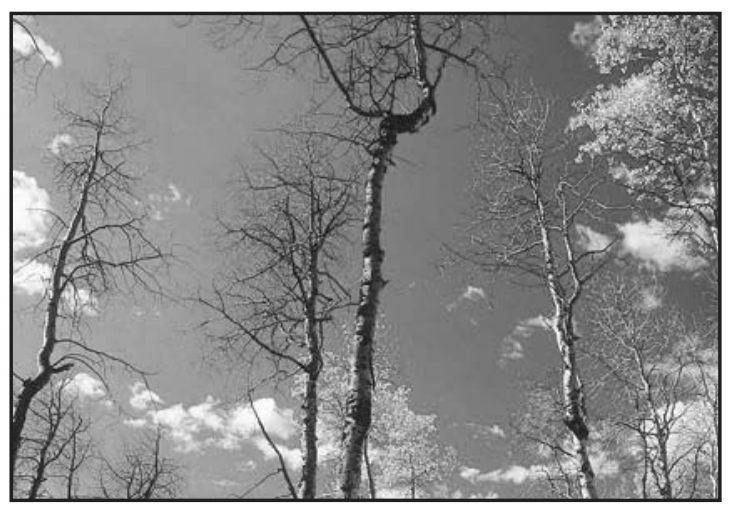

reta era uma fonte mediada ou mediatizada, ou seja, uma informação baseada em outras informações não testemunháveis (Aróstegui, 2001).

A fonte voluntária ou testemunhal é aquela que tem constituído a memória oficial das sociedades. É o reflexo do "imaginário" que os componentes de um grupo constroem, de sua mentalidade e ideologia. É a que reflete, portanto, o conflito interno de toda sociedade. Ao contrário da fonte involuntária, que trata de todos aqueles vestígios do homem que se tem conservado sem que este se tenha proposto, conscientemente, à sua conservação como "testemunho histórico" (Aróstegui, 2001).

Segundo o critério taxonômico qualitativo, aqueles documentos históricos cujo valor informativo reside, em primeiro lugar, em sua própria materialidade (os restos arqueológicos em geral) precisam, sem dúvida, de um tratamento diferente daqueles outros cuja identidade e valor residem "no que dizem", em seu conteúdo intelectual. Dessa maneira, estabelece-se uma clara distinção entre fontes material e cultural. Estas últimas são praticamente todas as existentes que não são fontes arqueológicas, todas aquelas escritas, faladas, simbólicas ou audiovisuais que transmitem uma mensagem em linguagem mais ou menos formalizada (Aróstegui, 2001).

Para este autor, as fontes culturais escritas podem ser narrativas ou não narrativas, as quais são categorias também centrais no que é o discurso textual. Assim, as fontes não narrativas são uma categoria muito genérica que exclui uma categoria bastante homogênea, mas extensíssima: todo o que é o relato. Em princípio, trata-se de uma distinção clara, mas que permite sutilezas e distinções, de forma que a partir de uma ou de outra se pode extrair um trabalho histórico bem distinto.

A história tradicional era construída, essencialmente, sobre fontes narrativas, que eram já em si mesmas uma "história" enquanto narração. Em matéria de fontes, a moderna historiografia reside no uso mais amplo das fontes não narrativas. Nesse sentido, Arósgueti (2001, pág. 388) pontua que a grande revolução tecnológica que o mundo tem experimentado no último quarto do século $\mathrm{XX}$ e início do século XXI refere-se às possibilidades dessa revolução dada a digitalização, a informação mediante a imagem de todo tipo (fotografia, imagem, a conjunção de imagem, som e texto, as chamadas multimídias), o que representa grande mudanças nas chamadas fontes tradicionais de informação histórica. Dessa maneira, hodiernamente, a aparição e o aumento constante do uso de materiais (como fontes) de outro gênero, cabe ressaltar que a novidade está junto ao advento de outro tipo de registros não verbais, senão visuais ou sonoros. Novos tipos de recursos e sua conservação em suportes de memória exenta, ou seja, eletromagnéticos e digitalizados.

A fonte seriada é aquela, material ou cultural, que está composta de muitas unidades ou elementos homogêneos, suscetíveis de ser ordenados, numericamente ou não (Aróstegui, 2001).

Exemplo: um arquivo policial de ocorrências de um determinado período de tempo; os prontuários dos pacientes de um dado hospital, ou anuários estatísticos de uma série de anos sobre os dados contáveis de uma empresa, etc. Desse modo, umas fontes apresentam-se seriadas e outras não estão seriadas por sua natureza, mas são seriáveis. Por exemplo: um conjunto de depoimentos, os discursos políticos de uma pessoa, etc. Infere-se, por conseguinte, que a condição de seriadas ou não alude, essencialmente (mas não de forma exclusiva), à distinção que pode ser feita nas fontes, entre aquelas que apresentam (ou delas se pode extrair) um conteúdo que se expressa numericamente, frente às que não têm essa possibilidade.

\section{As fontes no transcurso da história}

No século XVII, época que remonta a Idade Média, com Papebroche e Mabilion, as escolas classificavam-nas em autênticas e falsas. Posteriormente, no século XIX, a pesquisadora 
Juana Maria Hernandez Conesa (1995) relata que ocorreram as primeiras classificações de fontes, mais completa possível para àquela época.

Exemplo disso, é encontrado na obra de J. Lelewel intitulada "Historika - Metodologia de la Historia" (1815), por meio da divisão:Tradicional relatos orais-, Fontes escritas - monumentos silenciosos do passado - e Fontes escritas, bem como é possível de se encontrar na obra "Historika" (1922) de autoria de M. Handelsman com a classificação de Fontes indiretas - tradicionais - e as Fontes diretas - as demais. Nesse século G. Labuda rompeu com as classificações das fontes propostas, propondo a divisão para fontes ergotécnicas, sociotécnicas, psicotécnicas e tradicionais (Conesa, 1995).

As fontes ergotécnicas são aquelas referentes às atividades existentes, e indiretamente, ligadas às atividades sociais e mentais; as sociotécnicas refletem os processos de interação social; as psicotécnicas se referem ao papel da consciência em transformação pelas condições materiais e sociais da existência humana e as tradicionais refletem a memória do passado (Conesa, 1995).

Como se pode observar, a maioria das classificações propostas apresenta limitações sejam semânticas ou materiais. Neste sentido, Maria Juan Hermandez Conesa sugeri o uso da classificação apresentada na obra "Metodologia de la Historia" (1973) de autoria de Topolsky, a saber: fontes diretas e indiretas, e fontes escritas e não escritas.

Para tanto, a mesma autora disponibiliza um quadro aos leitores no sentido de sua aplicabilidade.

Quadro número 1: Fontes Diretas e Indiretas
Este quadro deve ser utilizado mediante articulação com a decodificação das fontes, ou seja, é preciso considerar: a informação, a pessoa que a recebeu; o canal através do qual se pode receber a informação e o código que determinou o modo que essa informação foi passada pelo receptor. Ademais, códigos como o lingüístico, terminológico, gráfico, psico-social e espiritual devem ser de conhecimento do pesquisador no que se refere ao objeto de pesquisa e a delimitação institucional, geográfica e temporal a ser utilizada (CONESA, 1995).

Conesa registra também que classificações combinadas podem produzir bons resultados, mas isso depende da peculiaridade do processo cognitivo histórico e dos procedimentos adotados pelo pesquisador (Conesa, 1995).

Por outro lado, a utilização desta classificação com massa documental densa, entende-se que ela consome um espaço temporal considerável em horas, segundo o que José González Siles propugnou no sentido de ser esta classificação um "capricho da historia", seja pela praticidade e clareza.

Por outro ângulo, Kossoy - pesquisador que destinou a tipologia das fontes com interesse para as imagens ressalta que, a tal tipologia deve vir ao encontro da praticidade e clareza na categorização das fontes, sendo elas: escritas, iconográficas, orais e objetos (Kossoy, 2001).

A fonte escrita - como registros escritos e de abrangência fundamental para as informações transmitidas sob forma original manuscrita, de reprodução gráfica ou impressa; iconográfica - em especial, as fotografias, que podem ser aplicadas às imagens, em geral; oral - depoimento e entrevista gravada e objeto - vestígios materiais que sobreviveram ao tempo (Kossoy, 2001). Mesmo diante do exposto acima, entende-se que o excesso de documento compromete o rigor metodológico da pesquisa. Para isso, é necessária a delimitação do uso da massa documental - corpus do estudo, por meio de critérios de exclusão e inclusão com aderência Fonte: Esquemal.4 (Conesa, 1995) ao objeto, ao se delimitar a documentação. Sendo 
assim, a delimitação da massa documental decorre da diversidade de fontes, requerendo que o pesquisador utilize, tais como: atas, memorandos, leis, resoluções, jornais, revistas, fotografias, filmes e artefatos (Cadiou, Coulomb, Lemonde e Santamaria, 2007).

Desta forma, se entende que, após a delimitação do corpus do estudo seja prudente aplicação de uma ou mais matrizes de análise de acordo com a especificidade da fonte utilizada, ou seja, ferramenta metodológica individualizada para aplicação em documentos oriundos da área jurídica, imprensa, imagem e outras.

Cabe, porém, destacar que a aplicação das matrizes, como ferramenta de análise das fontes, não impede as critica interna e externa. Para Aróstegui (2001), a contribuição da Escola de Annales foi decisiva para a crítica hodierna feita às fontes, destacando que o texto, em si mesmo, deve ser visto como algo inacabado, devendo ser interrogado sobre a veracidade, bem como a possibilidade de sentido extraído da essência do documento. Em suma, o pesquisador não se limita à discussão acerca da verdade do documento que se lhe apresenta, mas busca o sentido no contexto da produção, mesmo diante da possibilidade da "inveracidade", que reveste sua intencionalidade. Com isto, Aróstegui alerta para a ampliação das fontes sem se comprometer com a questão do que seja ou não a "verdade" documental, mesmo assim o documento poderá ser considerado como fonte histórica. Aróstegui, 2001).

Ainda sobre a crítica das fontes, estas podem ser indagadas no sentido de serem cópias ou originais. Em outras palavras, cabe analisá-las, quando necessário, no sentido da química, física e Raio X. Outro procedimento a ser realizado com as fontes, é a aplicação de critérios relativos à credibilidade, em especial, à triangulação das fontes (AlvesMazzotti e Gewandsznajder, 2001).

A triangulação das fontes permite o pesquisador especular, inferir e construir assertivas com risco menor de equivocar-se. Logo, esta ferramenta metodológica - triangulação - faz com que o pesquisador ao construir o texto de pesquisa lhe proporcione um tempo de vida mais longo até que outros estudos retifiquem ou até mesmo ratifiquem os dados analisados e discutidos.
Esquema 1: Representação da triangulação das fontes

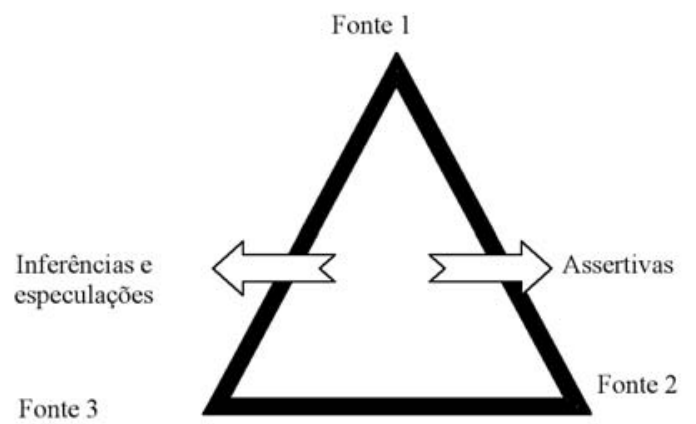

O esquema número um representa a materialização do mental sobre a triangulação das fontes, mesmo que sejam múltiplas, representam a possibilidade de análise sistemática, englobando: Interpretação dos dados; Síntese e Produto final no sentido da produção de artigo, monografia, dissertação, tese e relatório de pesquisa.

\section{Fontes ético-legais em estudos históricos}

Os legisladores da enfermagem, em matéria de ensino e exercício, têm uma grande parcela de responsabilidade ao facilitarem ou dificultarem o processo de reconhecimento social da profissão da enfermagem, definindo quem seus agentes sociais legítimos e, com isto, estabelecendo atribuições (competências) ao enfermeiro, identificando-o como um profissional de nível universitário, e considerando as múltiplas competências da sua formação. Além disso, a legislação pode constituir-se em importante instrumento rumo à autonomia profissional, porque ela pode legitimar conquistas de uma classe ou categoria profissional organizada, na luta pelo seu espaço social, sua identidade coletiva, a preservação dos valores e de sua memória como uma construção coletiva e dialética.

Cabe pontuar que na abordagem histórica das fontes legais, o entorno não pode delimitar-se ao tempo da promulgação de uma dada legislação, como por exemplo, a Lei de Diretrizes de Base (LDB) da Educação Nacional - a qual define e regulariza o sistema de educação brasileiro nos princípios presentes na Constituição Federal, de 1988. É preciso anteceder temporalmente à LDB, abordando e analisando outras legislações concer- 
nentes ao objeto (no caso a educação). A abrangência temporal de análise dos dispositivos legais anteriores à LDB $n^{\circ} 4024 / 61$, por exemplo, requer uma visão mais ampla dos contornos sociais, políticos e ideológicos e dos desdobramentos de questões dessa ordem envoltas ao ensino de enfermagem no Brasil no contexto da criação dessa lei. Assim, o historiador deve discutir quem são ou foram os agentes sociais influentes à época da propositura de uma legislação, quais foram as forças políticas que nortearam o processo de sua elaboração, dentre outros aspectos igualmente relevantes, acerca, por exemplo, da existência de escolas de enfermagem no contexto estudado. Assim, a busca de fontes legais não é suficiente em um estudo histórico, requerendo outras fontes, que iluminarão melhor a compreensão e análise dos achados.

No caso da LDB, já mencionada, ressalta-se o papel da Lei no 775/49 - que é uma legislação que regulamentava o ensino da enfermagem no Brasil, na década de 1940, a qual deixava clara a contradição sobre à acessibilidade ao curso de enfermagem. Se, por um lado, era requerido o secundário completo; por outro, permitia-se o ingresso de candidatas com curso ginasial. Esta contradição teria sido totalmente superada pela LDB. Assim se revelou a necessidade de sanar aquela contradição, considerando-se o fato de que não havia consenso antes da LDB de 1961, em relação aos requisitos para admissão ao curso de enfermagem.

A Escola de Enfermagem Anna Nery exigia o diploma de conclusão de curso normal ou equivalente. Outras escolas não faziam essa exigência, como a da Cruz Vermelha Brasileira e Escola Profissional de Enfermeiros e Enfermeiras, atual Escola de Enfermagem Alfredo Pinto, da Universidade Federal do Estado do Rio de Janeiro, que seguiam legislação própria, relacionada ao Ministério da Guerra (no caso da Cruz Vermelha) ou obedecia ao Decreto 791/1890, vinculado ao Ministério da Justiça. Ora, essa foi uma luta dos três ministérios (da Educação e Saúde, da Guerra e do Interior), pois tinham o mesmo nível hierárquico.

As leis são documentos e importantes fontes para os estudos históricos. Há que se considerar, entretanto, que na história tradicional (positivista), o documento correspondia ao texto, por exemplo, o Código de Direito Canônico, o direito da Igreja. Associando-se, portanto, o documento à "prova", ao direito, tanto que se diz: "não há história sem documento" (Fustel de Coulanges, 1961). A preocupação principal do historiador referia-se à autenticidade do documento. Já na perspectiva de Marc Bloch (1941-42), seria uma grande ilusão imaginar que a cada problema histórico corresponderia um tipo de documento especializado para esse fim. Nesse sentido, o que transforma o documento é a sua utilização pelo poder. Considerando-se que o documento ou o "corpus" documental não é qualquer coisa que fica por conta do passado; ao contrário, representam produto da sociedade que os fabricou, segundo as relações de forças que ali detinham o poder e o domínio do saber.

Daí a importância de se fazer a crítica aos documentos (fontes) e de se fazer a triangulação: revelando-se contradições ou inconsistências. É preciso perguntar-se quem os engendrou? Que interesses defendiam? Quais forças político-ideológicas de dominação estavam presentes? Quem criou a lei e a sancionou? Quais os interesses que defendiam uma dada lei? Por conseguinte, a legislação, enquanto "corpus" documental e monumento refletem as relações de poder (Estado) - que estabelecem quem detém a legitimação para produzi-las. Portanto, a legislação, enquanto monumento, representa jogos de forças ideológicas presentes nas relações sociais.

No tocante às fontes legais, cabe pontuar, a priori, a existência de hierarquização. Assim, subordinam-se à Constituição Federal (CF) as

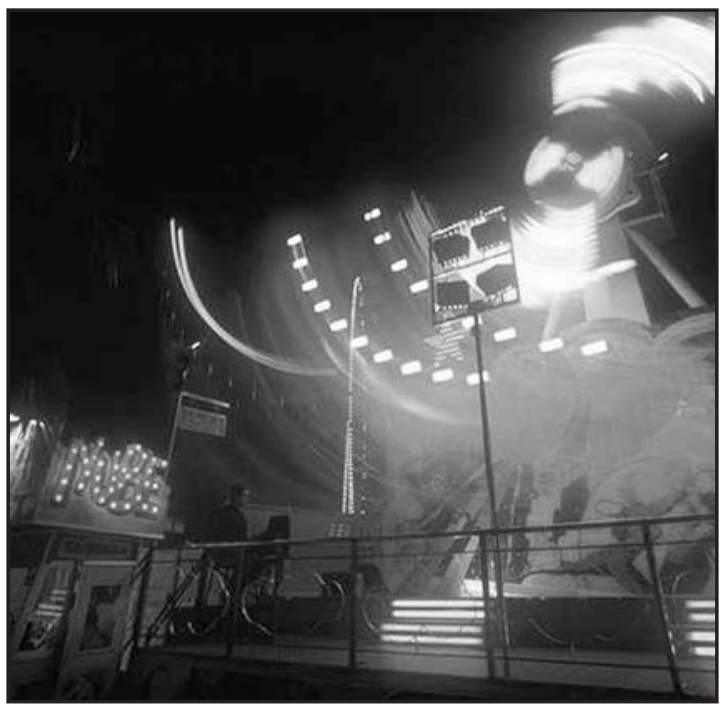


emendas ao texto constitucional, bem como as leis complementares, leis ordinárias, leis delegadas, medidas provisórias, decretos legislativos e resoluções, além de portarias, contratos e sentenças.

As leis complementares à Constituição destinam-se ao detalhamento de aspectos previstos na Constituição Federal do país, que se resguardam em princípios constitucionais auto-aplicáveis, dependendo de regulamentação que elas consubstanciam. Por exemplo, a Lei de Diretrizes de Base da Educação Nacional e o Código de Defesa e Proteção do Consumidor são exemplos de fontes documentais dessa natureza, ou seja, complementar à Constituição Federal do Brasil.

A lei ordinária refere-se a qualquer matéria e sua iniciativa segue o preceito constitucional, por exemplo, a lei do exercício profissional da enfermagem.

A lei delegada representa aquela delegação ao Presidente da República sendo feita por Resolução, especificando seu conteúdo e os termos do seu exercício. Como ato de força do poder executivo, existe, também, a chamada MP (Medida Provisória), a qual decorre de ato do Presidente da República com força de lei para casos de relevância e urgência. Deve ser levada imediatamente ao conhecimento do Congresso Nacional, que a analisará e poderá convertê-la em lei. Cabe pontuar que a MP não convertida em lei no prazo de 30 dias, perde a eficácia, mas o Presidente poderá reapresentá-la.

O Decreto significa decisão, ordem, julgamento ou decisão que emana de autoridade competente para tal. De acordo com a autoridade que o expede, este pode ser um Dec. Legislativo, judiciário ou Decreto-lei. O primeiro, decorre de deliberações em que se consagra uma medida de caráter administrativo ou político do Congresso Nacional. Não pode estabelecer nem criar um direito novo, o que só pode ser feito por uma lei. O segundo é produto da designação dada, de modo geral, a toda decisão emanada de autoridade judicial, em caráter de ordem, a qual deve ser cumprida pelas partes interessadas. A própria sentença do juiz constitui um decreto judiciário, em que soluciona um litígio (demanda) de interesses. E o terceiro representa ato emanado do Poder Executivo, quando no seu fundo e na sua forma se equiparava às próprias leis, emanadas do Poder Legislação. É peculiar aos regimes de exceção e foi empregado no Brasil no Estado Novo e no período de regime militar.

As resoluções são instrumentos normativos que resulta de um ato da administração de um colegiado ou uma assembléia, contendo esclarecimentos, solução, deliberação ou regulamentação ou determinação sobre algum assunto (Oguisso, 2007).

A portaria, por sua vez, é um ato escrito por meio do qual uma autoridade qualquer na esfera dos três poderes (ministérios, secretarias de Estado, tribunais regionais, autarquias), tais como ministro de Estado, juiz, reitor de universidade, etc, dá instruções sobre a execução de leis ou serviços, nomeia ou designa funcionários e aplica medidas de ordem disciplinar a subordinados (Freitas, 2005).

A doutrina constitui importante fonte jurídica e representa o domínio das lições, ensinamentos e descrições explicativas do direito posto, elaboradas pelos mestres e pelos juristas especializados (Carvalho, 2000).

A jurisprudência é outra fonte jurídica, que consiste em um conjunto de decisões judiciais que apontam para tendências a serem seguidas por decisões judiciais. O uso da hermenêutica jurídica possibilita interpretar a legislação, visando preencher suas lacunas ou casos omissos. Entretanto, em matéria de fonte, o Juiz não se obriga a seguir os julgados que o antecedem, podendo, portanto, inovar e criar novas jurisprudências (Carvalho, 2000).

Em suma, se para a história hierarquizar as fontes constitui uma tipologia obsoleta, para o direito representa uma prática admissível, haja vista a necessidade do legislador de considerar a própria instituição da hierarquização das normas jurídicas. Como fontes históricas devem prevalecer as normas constitucionais sobre as demais. Sendo assim, se houver uma legislação "maior" regulamentando a mesma matéria, o pesquisador não deverá declinar do valor jurídico da fonte. Deve-se entender que a hierarquização das leis é obsoleta em uma perspectiva histórica mais atual; por outro ângulo, é admissível dizer que tal postura representa um diferencial. Faz-se mister, entretanto, considerar a necessidade de triangulação das legislações com outras fontes históricas e legais se considerarmos a necessidade da aplicação de maior rigor metodológico nos estudos históricos acerca da profissão da enfermagem. 


\section{Considerações finais}

Em relação às possibilidades da seleção das fontes para a consecução de estudos em história da enfermagem, percebe-se que, atualmente, o conceito de fonte abrange uma densa massa documental no sentido de englobar documentos escritos, iconográficos, fontes orais e objetais. Dessa maneira, o movimento da História Nova tem contribuído para o esgarçamento do conceito de documento e, por conseguinte, a massa documental adquire novo status, porém há limitações das classificações das fontes.

Alguns autores têm propugnado por determinados tipologias de fontes, de acordo com seus interesses e necessidades, conforme requerem seus objetos de investigação, o que, por outro lado, não o exime do compromisso com a idéia de complementariedade e ampliação do uso de outras fontes, pois o pesquisador não deve se limitar à exclusividade de uma massa documental, embora essa possa ser seu foco temático.

A presente contribuição, enquanto atualização na problemática de tipologias das fontes históricas, não tem a pretensão de esgotar a discussão acerca dessa temática. Por outro lado, não se pode negligenciar o fato de que existem possibilidades de uso de fontes virtuais e quiçá holográficas. Em termos de inovação na utilização de fontes históricas, cabe pontuar aquelas atinentes aos documentos legais, pois têm sido ainda pouco utilizadas como ferramenta importante para evidenciar a memória histó- rico-legal da profissionalização da enfermagem no Brasil.

\section{Referências:}

- Alves-Mazzotti, A.J. e Gewandsznajder, F. (2001): Método nas ciências naturais e sociais: pesquisa quantitativa e qualitativa. São Paulo (Brasil).Pioneira.

- Aróstegui J. (2001): La investigación histórica: teoria y método. Barcelona (Espanha). Crítica

- Bloch M. (2003): Apologie pour 1’histoire ou métier d’historien. Paris: Colin; 1949. In: Le Goff J. História e memória. São Paulo (Brasil).Ed. Unicamp.

- Cadiou F.; Coulomb, C.; Lemonde, A.; Santamaria, Y. (2007): Como se faz história - historigrafia, método e pesquisa. Petrópolis (Brasil), Vozes.

- Carvalho P.B.(2000): Curso de direito tributário. 13ª Ed.. São Paulo (Brasil): Saraiva.

- Conesa J. M. H. (1995): Historia de la Enfermería: um análisis histórico de los Cuidados de Enfermería. Madrid (Espanha). Interamericana/McGraw.

- Coulanges F.N.D. (2003): La monarchie franque. In: Histoire des institutions poliques de l'ancienne France. Tomo III. Paris: Hachette; 1875-1889. In: Le Goff J. História e memória. São Paulo (Brasil). Ed. Unicamp.

- Freitas G.F.(2005): Conceituação sobre direito e normas éticas e legais. In: Oguisso T (org). Trajetória histórica e legal da enfermagem. São Paulo (Brasil). Manole.

- Kossoy B. (2001): Fotografia e História. São Paulo (Brasil). Ateliê Editorial.

- Le Goff J. (2003):História e memória. São Paulo (Brasil). Ed. Unicamp.

- Oguisso T. (2007): O exercício da enfermagem: uma abordagem ético-legal. Rio de Janeiro (Brasil). Koogan Guanabara.

- Samaran C. (org) (2003): L’histoire et ses methods. XI. Paris: Gallimard; 1961. Encyclopédie de la Pléiade. In: Le Goff J. História e memória. São Paulo (Brasil). Ed. Unicamp.

- Siles J. (1999): Historia de la Enfermería. Alicante (Espanha): Aguaclara.

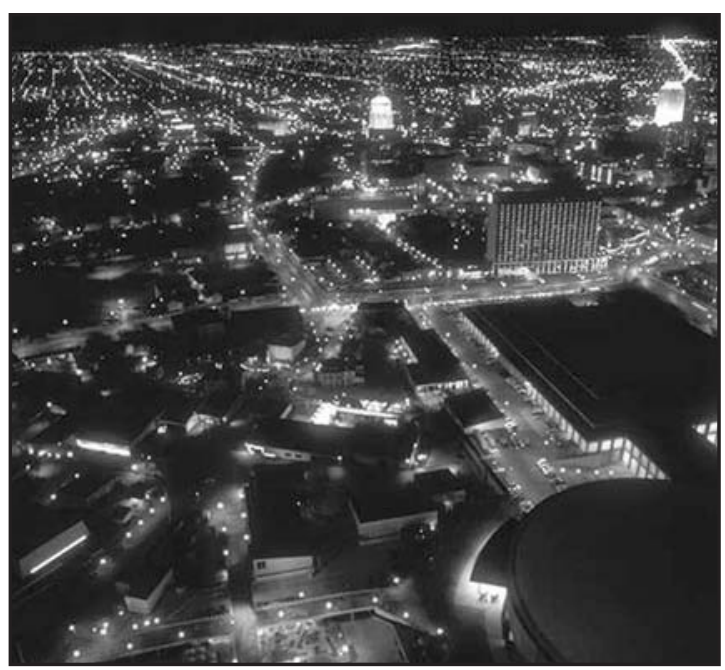

